Review

\title{
Efficacy of sequential therapies with sorafenib-sunitinib versus sunitinib-sorafenib in metastatic renal cell carcinoma: A systematic review and meta-analysis
}

\author{
Tingyu Wen ${ }^{1}$, Hai Xiao² ${ }^{2}$ Chao Luo ${ }^{3}$, Li Huang ${ }^{4}$ and Meimei Xiong ${ }^{5}$ \\ ${ }^{1}$ College of Basic Medical Sciences, Gannan Medical University, Ganzhou, China \\ 2 Department of Pathology, Gannan Medical University, Ganzhou, China \\ ${ }^{3}$ Department of Urology, People's Hosptial of Pingxiang, Pingxiang, China \\ ${ }^{4}$ Department of Oncology, The First Affiliated Hospital of Gannan Medical University, Ganzhou, China \\ ${ }^{5}$ Department of Nephrology, The First Affiliated Hospital of Gannan Medical University, Ganzhou, China \\ Correspondence to: Hai Xiao, email: xh669168@sina.com \\ Keywords: renal cell carcinoma, sorafenib, sunitinib, targeted agents, meta-analysis \\ Received: November 10,2016 Accepted: January 09, $2017 \quad$ Published: January 15, 2017
}

\section{ABSTRACT}

The most efficient sequence of targeted agents for metastatic renal cell carcinoma patients has yet to be identified. Whether the sequence of sorafenib and sunitinib really matters is controversial and not answered clearly until now. This meta-analysis aims to estimate the efficacy of receptor tyrosine kinase inhibitors sorafenib-sunitinib and sunitinib-sorafenib for metastatic renal cell carcinoma, on the outcome of first-line progression-free survival, second-line progression-free survival, total progressionfree survival and overall survival.

We searched PubMed, Embase, Cochrane Library and ClinicalTrails.gov for eligible studies. Data were analyzed using random or fixed effects model depending on the heterogeneity of the eligible studies. Heterogeneity across studies were analyzed using $Q$ and $I 2$ statistics.

Of 902 identified studies, ten were qualified in our analysis ( $N=1732$ patients). Sorafenib-sunitinib yielded no statistically significant benefit in first-line progressionfree survival (fixed effects; HR $=0.95 ; 95 \% C I 0.75-1.21 ; p=0.702$ ), total progressionfree survival (random effects; HR $=0.92 ; 95 \% \mathrm{CI} 0.71-1.19 ; p=0.531$ ) and overall survival (fixed effects; $\mathrm{HR}=0.89 ; 95 \% \mathrm{CI} 0.72-1.09 ; p=0.257$ ), compared with sunitinib-sorafenib. Second-line progression-free survival was longer for sorafenibsunitinib than sunitinib-sorafenib (fixed effects; $H R=0.55 ; 95 \% C I 0.44-0.68 ; p=$ 0.000).

Sequential therapies with sorafenib and sunitinib is well tolerated and efficient in $\mathrm{mRCC}$. However, there are no evidence supported that sorafenib-sunitinib has the superiority to sunitinib-sorafenib in sequence. The ideal sequence of targeted agents requires further elucidation.

\section{INTRODUCTION}

Metastatic renal cell carcinoma (mRCC) is the spread of the primary renal cell carcinoma from the kidney to other organ [1]. Due to its mild clinical signs, as many as $30 \%$ of people have metastatic disease by the time they are diagnosed with renal cell carcinoma [2]. The most common sites for metastasis are the lymph nodes, lungs, bones, liver and brain [3]. mRCC is notoriously resistant to available chemotherapy and radiotherapy [4], and the 5 year survival rate for mRCC remains under $15 \%$ [5].

Nowadays, the National Comprehensive Cancer Network Kidney Cancer Panel (NCCN, Version 2.2017) recommends sunitinib and sorafenib as preferred category 1 and category 2A options for first-line treatment of patients with relapsed or medically unresectable predominantly clear cell stage IV renal carcinoma, respectively [6]. Moreover, sunitinib and sorafenib has 
Table 1: Summary of included studies evaluating the efficacy or safety of sequential therapies in metastatic renal cell cancer

\begin{tabular}{|c|c|c|c|c|c|c|c|c|c|c|c|c|c|c|}
\hline \multirow[t]{2}{*}{ Study } & \multirow[t]{2}{*}{ Year } & \multirow[t]{2}{*}{ Race } & \multirow[t]{2}{*}{ Design } & \multirow{2}{*}{$\begin{array}{l}\text { Median } \\
\text { Follow-up }\end{array}$} & \multirow[t]{2}{*}{ Sequence } & \multirow{2}{*}{$\begin{array}{l}\text { Patients, n } \\
(847)(885)\end{array}$} & \multirow{2}{*}{$\begin{array}{c}\text { Mean age } \\
\text { (years) }\end{array}$} & \multirow[t]{2}{*}{ Male } & \multirow{2}{*}{$\begin{array}{l}\text { Clear-cell } \\
\text { rate }(\%)\end{array}$} & \multicolumn{3}{|c|}{ Median PFS, months } & \multirow{2}{*}{$\begin{array}{l}\text { Median OS } \\
\text { (months) }\end{array}$} & \multirow{2}{*}{$\begin{array}{l}\text { NOS } \\
\text { score }\end{array}$} \\
\hline & & & & & & & & & & PFS1 & PFS2 & PFS & & \\
\hline \multirow{2}{*}{$\begin{array}{l}\text { Sablin et al } \\
{[11]}\end{array}$} & \multirow[t]{2}{*}{2009} & \multirow[t]{2}{*}{ French } & \multirow[t]{2}{*}{ Retro } & \multirow{2}{*}{$\mathrm{N} / \mathrm{A}$} & So-Su & 68 & 60 & 52 & 82 & 6.1 & 6.5 & N/A & 31.5 & 8 \\
\hline & & & & & Su-So & 22 & 56 & 18 & 86 & 5.1 & 4.0 & N/A & 19.1 & \\
\hline \multirow{2}{*}{$\begin{array}{l}\text { Dudek et al } \\
\text { [9] }\end{array}$} & \multirow[t]{2}{*}{2009} & Dutch, & \multirow[t]{2}{*}{ Retro } & $86.9 / 43.9$ & So-Su & \multirow[t]{2}{*}{29} & 62 & 22 & 86 & $5.1^{\mathrm{a}}$ & $4.7^{\mathrm{a}}$ & $18.2^{\mathrm{a}}$ & 23.8 & 8 \\
\hline & & American & & weeks & Su-So & & 58.5 & 16 & 80 & $5.8^{\mathrm{a}}$ & $2.2^{\mathrm{a}}$ & $8.6^{\mathrm{a}}$ & 10.5 & \\
\hline \multirow{2}{*}{$\begin{array}{l}\text { Porta et al } \\
{[18]}\end{array}$} & \multirow[t]{2}{*}{2011} & \multirow[t]{2}{*}{ Italian } & \multirow[t]{2}{*}{ Retro } & \multirow[t]{2}{*}{ N/A } & So-Su & 90 & 58 & 74 & 84 & 8.4 & 7.9 & 16.3 & $\mathrm{~N} / \mathrm{A}$ & 8 \\
\hline & & & & & Su-So & 99 & 60 & 67 & 87 & 7.8 & 4.2 & 12.0 & $\mathrm{~N} / \mathrm{A}$ & \\
\hline \multirow{2}{*}{$\begin{array}{l}\text { Herrmann } \\
\text { et al (QL)[17] }\end{array}$} & \multirow[t]{2}{*}{2011} & German & Retro & N/A & So-Su & 54 & total & total & Total & N/A & N/A & 12.1 & 28.8 & 5 \\
\hline & & & & & Su-So & 33 & 64 & 66 & 72 & N/A & N/A & 15.4 & 28.9 & \\
\hline Buchler et al & 2012 & Czech & Retro & $16.7 / 15.1$ & So-Su & 122 & 60 & 82 & 100 & N/A & N/A & 18.8 & 30.0 & 9 \\
\hline$[16]$ & & & & months & Su-So & 138 & 61 & 100 & 100 & N/A & N/A & 17.7 & 35.4 & \\
\hline Stenner et al & 2012 & Swedish & Retro & N/A & So-Su & 10 & 57.1 & $\mathrm{~N} / \mathrm{A}$ & 80 & 5.39 & 6.01 & N/A & N/A & 4 \\
\hline (QL) [12] & & & & & Su-So & 11 & 57.4 & N/A & 73 & 12.71 & 3.71 & N/A & $\mathrm{N} / \mathrm{A}$ & \\
\hline Calvani et al & 2012 & Italian & Retro & total 28 & So-Su & 15 & 70 & 12 & 73 & 6.0 & 11.0 & 20.0 & Undefined & 7 \\
\hline [14] & & & & months & Su-So & 18 & 61 & 11 & 83 & 7.5 & 3.0 & 10.0 & 27 & \\
\hline Alimohamed & 2013 & Canadian, & Retro & total 36 & So-Su & 152 & $\mathrm{~N} / \mathrm{A}$ & N/A & $\mathrm{N} / \mathrm{A}$ & 7.3 & 5.2 & N/A & 26.5 & 4 \\
\hline et al (QL) & [8] & American & & months & Su-So & 257 & $\mathrm{~N} / \mathrm{A}$ & $\mathrm{N} / \mathrm{A}$ & $\mathrm{N} / \mathrm{A}$ & 7.6 & 3.6 & N/A & 23.0 & \\
\hline Biondani et & 2014 & Italian & Retro & $66.6 / 37.1$ & So-Su & 125 & 60 & 77 & 38 & 12 & 14.1 & 26.1 & 35.3 & 7 \\
\hline al [15] & & & & months & Su-So & 104 & 62 & 15 & 14 & 12 & 8.0 & 20.0 & 27 & \\
\hline Eichelberg et & 2015 & German, & RCT & total 10.3 & So-Su & 182 & 64 & 139 & 90 & 6.9 & 5.4 & 12.5 & 31.5 & N/A \\
\hline al [13] & & Australian & & months & Su-So & 183 & 65 & 135 & 84 & 8.5 & 2.8 & 14.9 & 30.2 & \\
\hline
\end{tabular}

also been listed as category $2 \mathrm{~A}$ subsequent therapy options [6].

Sequential therapies with distinct targeted drugs have become a standard protocol when patients suffering from disease advanced during treatment [7]. Consequently, probing how to sequence molecular targeted drugs in an optimal way is essential for maximization of clinical benefit in patients with mRCC. Does the therapeutic order of sorafenib and sunitinib in $\mathrm{mRCC}$ really matter? Parts of recent retrospective studies have suggested that sorafenib followed by sunitinib ( $\mathrm{So}-\mathrm{Su}$ ) was optimal to sunitinib followed by sorafenib ( $\mathrm{Su}-\mathrm{So}$ ) in progressionfree survival and overall survival [8-12]. Nevertheless, a recent randomized controlled trial SWITCH [13] and several retrospective studies [14-17] argued that So-Su and Su-So offer similar clinical efficacy in mRCC, with no statistically differences.

Recognizing the divergent findings and that a single study might not be able to provide sufficient evidence into clinical recommendation. We therefore produced this systematic review and meta-analysis to evaluate the efficacy of So-Su versus Su-So on the outcome of firstline progression-free survival, second-line progressionfree survival, total progression-free survival and overall survival.

\section{RESULTS}

\section{Search results}

The search of PubMed, Embase, Cochrane Library and ClinicalTrails.gov provided 902 recordings total. In addition, manual search revealed 2 additional records. Then, 21 were selected for full-text review depending on pre-planned inclusion criteria. Finally, 7 studies were available for quantity analysis owing to their adequate quality and sufficient data. Other 3 studies were used as qualitative synthesis only. Full details of the selection process were disclosed in Figure 1 and the main characteristics of included studies were displayed in Table 1.

\section{Efficacy}

In a pooled analysis of 3 retrospective studies [8, 11, 18] (So-Su 173 patients, Su-So 139 patients) that assessed PFS1. The cumulative data showed that no significant difference between two groups in PFS1 (fixed effects; HR $=0.95 ; 95 \%$ CI, 0.75-1.21; $p=0.702)$. In RCT [13], 182 received So-Su and 183 received Su-So. PFS1 was similar among two arms $(\mathrm{HR}=1.19 ; 95 \% \mathrm{CI}, 0.93$ 1.52; log-rank $p=0.9)$. After combined retrospective and $\mathrm{RCT}$, also no significant difference in PFS1 was observed (fixed effects; HR $=1.06 ; 95 \%$ CI, 0.90-1.26; $p=0.484$ ) (Figure 2A). All analysis showed no heterogeneity, and 
the further influence analysis also showed the robustness of our results (Figure 4A).

Pooled analysis of 3 retrospective studies [8, 11, 18] (So-Su 173 patients, Su-So 139 patients) that assessed the PFS2 showed So-Su were more positive in reducing the risk of disease progression in second-line therapy than Su-So (fixed effects; $\mathrm{HR}=0.54 ; 95 \% \mathrm{CI}, 0.41-0.71 ; p=$ 0.000). In RCT [13] (103 vs 76), median PFS2 was longer for So-Su than for Su-So $(\mathrm{HR}=0.55$; 95\%CI, 0.39-0.78; $\log$-rank $p<0.001)$. After combined all studies, So-Su was still superior to $\mathrm{Su}-\mathrm{So}$ group (fixed effects; $\mathrm{HR}=0.55$; 95\%CI, 0.44-0.68; $p=0.000$ ) (Figure 2B). All analysis showed no heterogeneity, and the further influence analysis also showed the robustness of our results (Figure 4B).

Three studies $[8,15,16]$ (262 vs 260) assessed the PFS. The cumulative data of these studies showed no significant difference (random effects; $\mathrm{HR}=0.81 ; 95 \% \mathrm{CI}$, $0.52-1.27 ; p=0.365)$. In RCT [13] (182 vs 183), So-Su was not superior to $\mathrm{Su}-\mathrm{So}(\mathrm{HR}=1.01 ; 95 \% \mathrm{CI}, 0.77-1.32$; $\log$-rank $p=0.5)$. After combined, still no significant difference in PFS was investigated (random effects; HR
$=0.92 ; 95 \% \mathrm{CI}, 0.71-1.19 ; p=0.531)$ (Figure 3A). All analysis showed moderate-to-high heterogeneity, and the further influence analysis also showed the robustness of our results (Figure 4C).

Five studies [8, 9, 11, 15, 16] (359 vs 302) assessed the OS. The cumulative data of these studies showed no significant difference (fixed effects; $\mathrm{HR}=0.81 ; 95 \% \mathrm{CI}$, $0.62-1.07 ; p=0.133)$. In RCT [13] (182 vs 183), OS was similar in both arms $(\mathrm{HR}=1 ; 95 \% \mathrm{CI}, 0.73-1.37$; log-rank $p=0.5)$. After combined, also no significant difference in OS was observed (fixed effects; $\mathrm{HR}=0.89 ; 95 \% \mathrm{CI}$, $0.72-1.09 ; p=0.257$ ) (Figure 3B). All analysis showed moderate-to-high heterogeneity, and the further influence analysis also showed the robustness of our results (Figure 4D).

Additionally, some studies described with median survival, instead of $\mathrm{HR}$ and 95\%CI, were systemtically reviewed only. Herrmann et al [17] reported 54 patients in So-Su and 33 patients in Su-So group. The median PFS were 12.1 vs 15.4 months and the median OS were 28.8 vs 28.9 months. Stenner et al [12] reported 10 patients in So-Su and 11 patients in Su-So group. The median PFS1

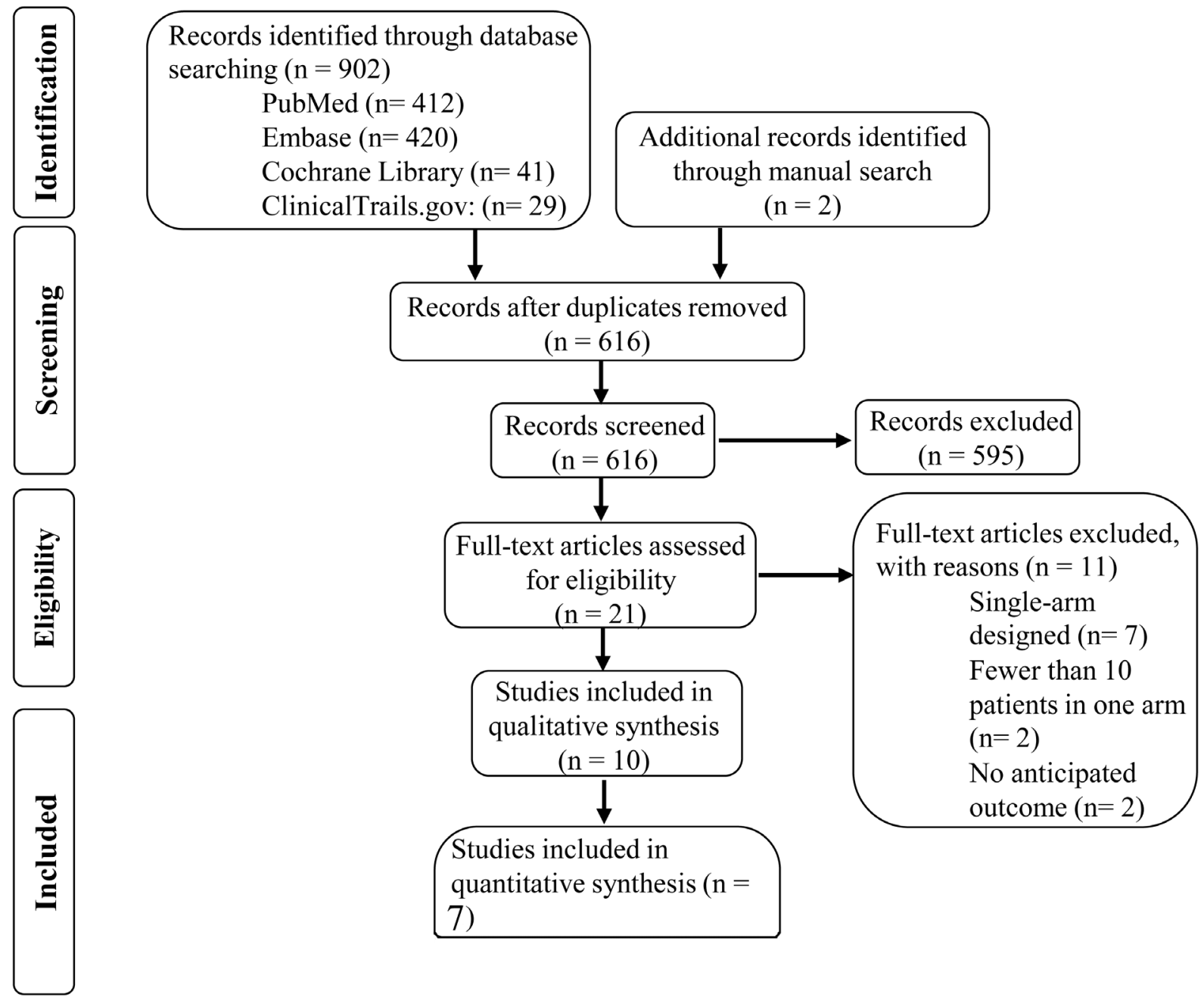

Figure 1: Study selection process. 


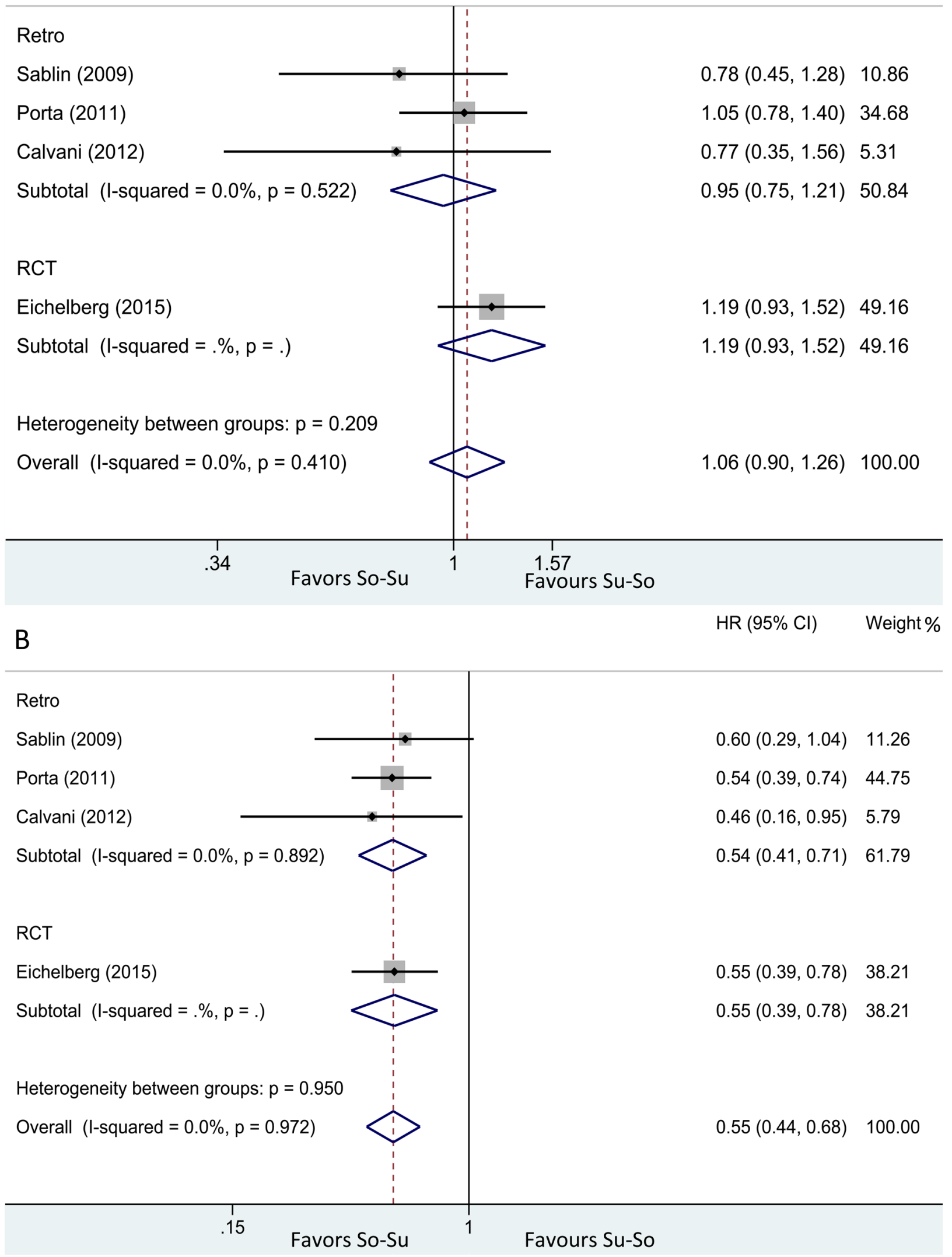

Figure 2: Hazard ratio for (A) PFS1, (B) PFS2 in overall population treated with So-Su over Su-So. 


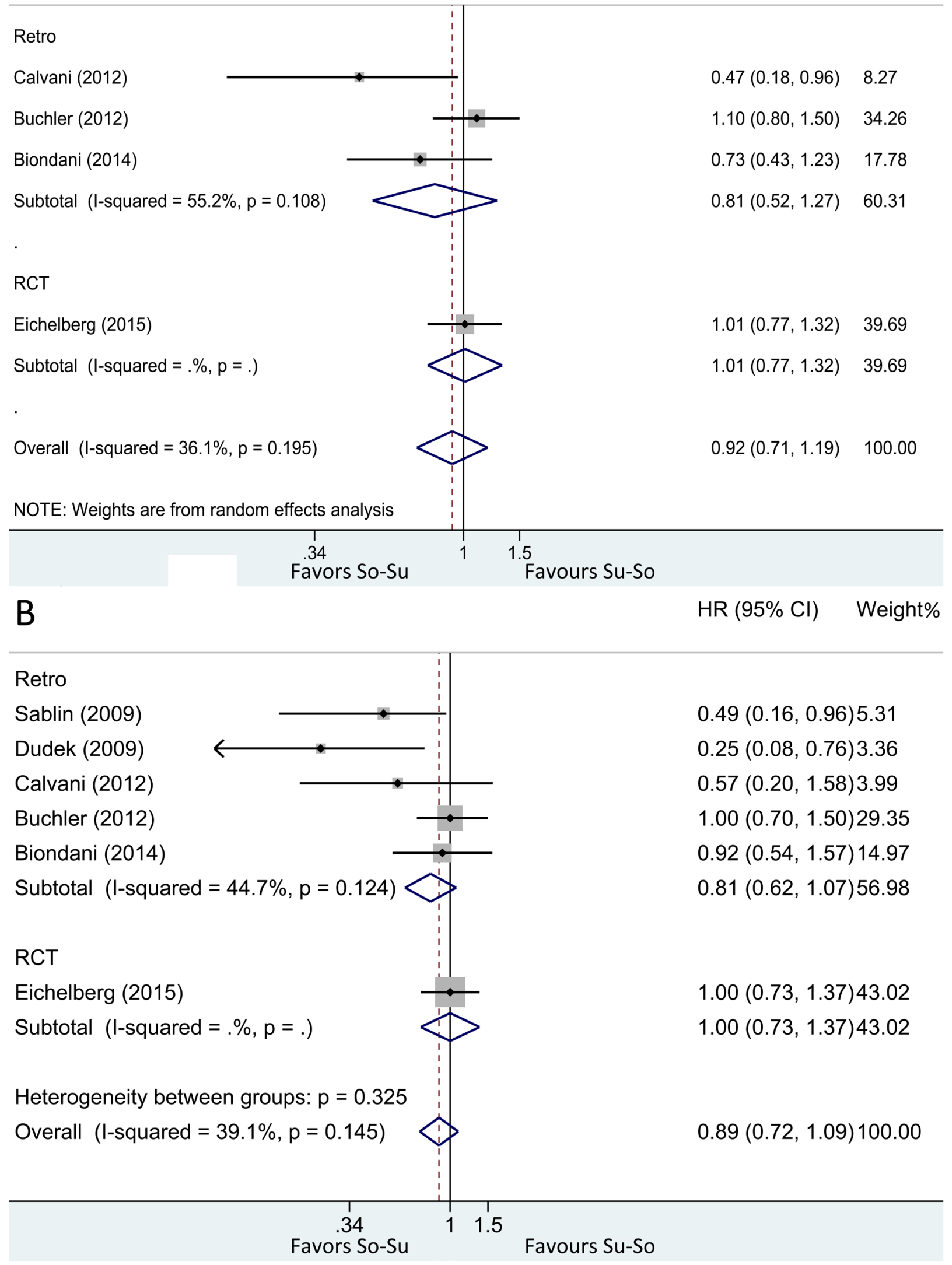

Figure 3: Hazard ratio for (A) PFS and (B) OS in overall population treated with So-Su over Su-So. 
were 5.39 vs 12.71 months and the median OS were 6.01 vs 3.71 months. Alimohamed et al [14] reported 152 in So$\mathrm{Su}$ and 257 in Su-So group. The median PFS1 were 7.3 vs 7.6 months. The median PFS2 were 5.2 vs 3.6 months and the median OS were 26.5 vs 23.0 months.

\section{Safety}

Data for serious adverse events were available from two studies $[13,16]$. The most frequently recording adverse events for sorafenib were diarrhea, hand-foot skin reaction. Adverse events for sunitinib were diarrhea, fatigue, hypertension, and nausea. Further toxicity profiles were displayed in Table 2.

\section{DISCUSSION}

In our present study, we investigated whether the therapeutic order of sorafenib and sunitinib in mRCC really mattered. We found that, compared with Su-So, SoSu offers no statistically significant benefit in PFS1, total PFS and OS. PFS2 was statistically longer for So-Su than $\mathrm{Su}-\mathrm{So}$. These data may lend support to that So-Su and SuSo provide similar overall clinical benefit in $\mathrm{mRCC}$ no
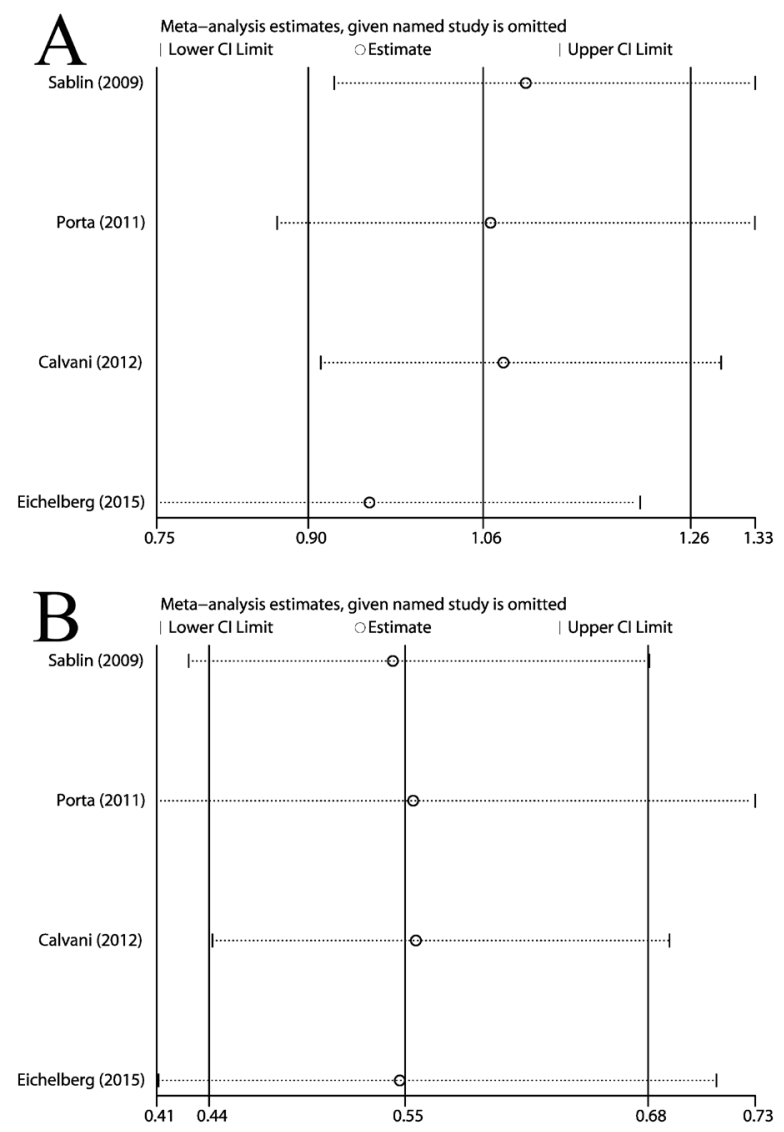

matter how to order them.

The approval of targeted therapies as the first-line drug represented a milestone in the treatment landscape for $\mathrm{mRCC}$ in the last decade [19]. However, single targeted agent is transient owing to the progressive nature of the disease [20]. Therefore, how to order these agents in an optimal way after disease advanced has become the major focus of the RCC realm. Furthermore, although the NCCN (Version 2.2017) recommends cabozantinib, nivolumab, lenvatinib plus everolimus and Axitinib as a category 1 preferred subsequent therapy option [6], the sunitinib and sorafenib are still essential for $\mathrm{mRCC}$ in most of Asian countries, due to differences in approvals in different countries [21]. The optimal sequence has not been determined. There were several clinical trials evaluating sequential targeted therapy in $\mathrm{mRCC}$. RECORD-3, a phase 2 randomized trial, have compared sequential everolimus-sunitinib to sunitinib-everolimus, and suggested that sunitinib-everolimus was a paradigm treatment at progression [22]. Besides, an international phase 3 trial has estimated temsirolimus versus sorafenib as second-line therapy after sunitinib in patients with mRCC [23]. It reported that temsirolimus did not show a benefit compared with sorafenib in PFS, but longer OS
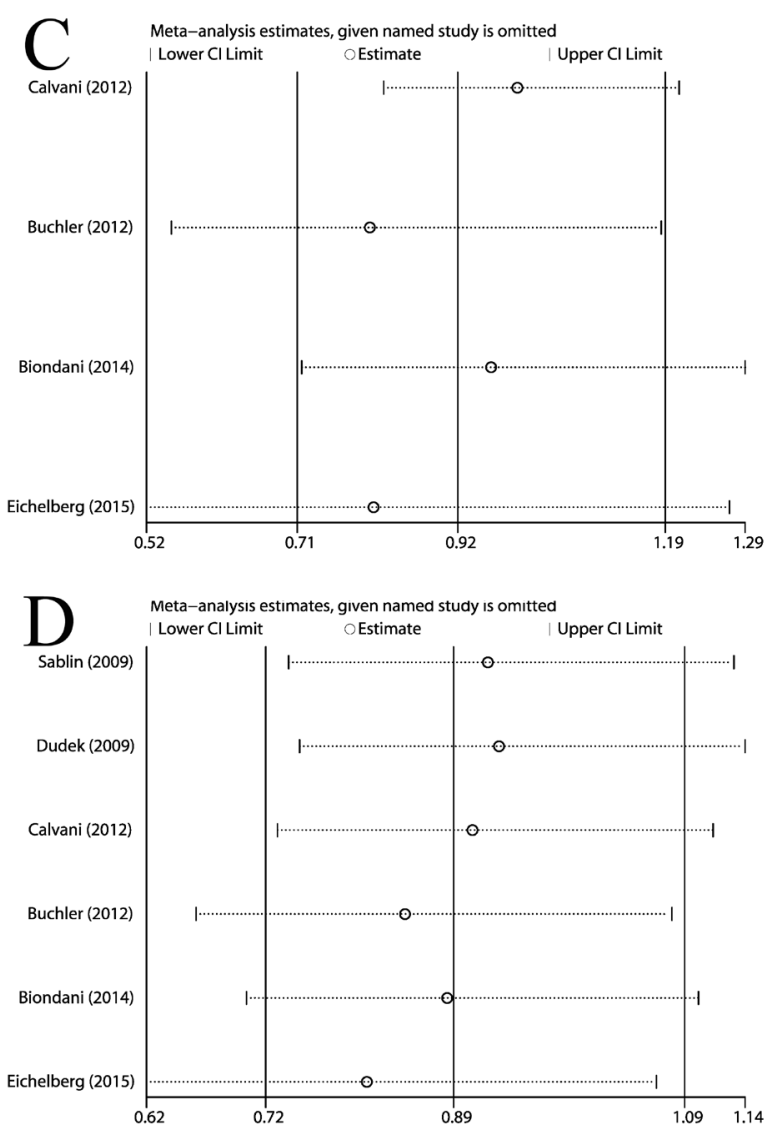

Figure 4: Influence analysis for (A) PFS1, (B) PFS2, (C) PFS and (D) OS in overall population treated with So-Su over SuSo. 
Table 2: Safety overview

\begin{tabular}{|c|c|c|c|c|c|c|c|c|}
\hline Adverse & Eichelber: & t al [13] & & & Buchler et & [16] & & \\
\hline Events, n (\%) & \begin{tabular}{|l|} 
First-line \\
So \\
$(n=177)$ \\
\end{tabular} & \begin{tabular}{|l|} 
Second-line \\
Su \\
$(n=103)$
\end{tabular} & \begin{tabular}{|l|} 
First-line \\
Su \\
$(n=176)$ \\
\end{tabular} & \begin{tabular}{|l|} 
Second-line \\
So \\
$(n=76)$
\end{tabular} & $\begin{array}{l}\text { First-line } \\
\text { So }(n=122)\end{array}$ & \begin{tabular}{|l} 
Second- \\
line Su \\
$(n=122)$
\end{tabular} & \begin{tabular}{|l|}
$\begin{array}{l}\text { First- } \\
\text { line Su } \\
(n=138)\end{array}$ \\
\end{tabular} & \begin{tabular}{|l|}
$\begin{array}{l}\text { Second- } \\
\text { line So } \\
(n=138)\end{array}$ \\
\end{tabular} \\
\hline Any AEs & $172(97)$ & $90(87)$ & $172(98)$ & $64(84)$ & $82(67)^{\mathrm{a}}$ & $40(33)^{\mathrm{b}}$ & $64(46)^{b}$ & $50(36)^{\mathrm{a}}$ \\
\hline At least one $\mathrm{AE}$ & - & - & - & - & $92(75)^{c}$ & & $88(64)^{\mathrm{c}}$ & \\
\hline Serious AEs & $88(50)$ & $43(42)$ & $81(46)$ & $19(25)$ & $33(27)^{d}$ & $17(14)^{\mathrm{e}}$ & $29(21)^{d}$ & $14(10)^{\mathrm{e}}$ \\
\hline At least one $\mathrm{AE}$ & - & - & - & - & $41(34)^{\mathrm{f}}$ & & $40(29)^{\mathrm{f}}$ & \\
\hline Grade $3 / 4 \mathrm{AE}$ & $117(66)$ & $53(51)$ & $118(67)$ & $27(36)$ & - & - & - & - \\
\hline AEs related to deaths & $12(6.7)$ & $1(1.0)$ & $16(9.1)$ & $2(2.6)$ & - & - & - & - \\
\hline
\end{tabular}

Abbreviations: AE, adverse event; So, sorafenib; Su, sunitinib.

${ }^{a}$ The difference was statistically significant $(P<0.001)$.

${ }^{\mathrm{b}}$ The difference was statistically significant $(P=0.031)$.

${ }^{\mathrm{c}}$ The difference was statistically significant $(P=0.045)$.

${ }^{\mathrm{d}}$ The difference was statistically significant $(P<0.001)$.

eThe difference was not statistically significant $(P=0.146)$.

${ }^{\mathrm{f}}$ The difference was not statistically significant $(P=0.425)$.

observed with sorafenib indicates sequencing sunitinib and sorafenib may benefit patients with mRCC. Consequently, to investigate the optimal sequence for the sorafenib and sunitinib in mRCC may be urgent and significant, at least in most of Asian countries.

Review of the literature, several retrospective and $\mathrm{RCT}$ researches have estimated the role of So-Su versus Su-So in patients with $\mathrm{mRCC}$, but with divergent results. Five retrospective studies, which reported by Sablin, Dudek, Porta, Stenner and Calvani et al $[8,9,11,12$, 18], suggested So-Su was superior to Su-So. However, Herrmann, Buchler, Alimohame, Biondani, Eichelberg et al [13-17] argued that So-Su and Su-So provide similar clinical benefit in $\mathrm{mRCC}$, with no significant differences.

A pooled analysis of this topic was performed by Stenner et al [12] in 2012, but we can discover various drawbacks on it when weighing this article in mind. In that, median combined PFS was 12.1 months on Su-So to 15.4 months on $\mathrm{So}-\mathrm{Su}$ (95\%CI, 1.45-5.12, $p=0.0013$ ) among 853 participants. No statistically difference in median PFS1 was noted (median PFS1 was on average 0.62 months longer on So-Su, 95\%CI, -1.01 to 2.26 , $p=0.43)$. PFS2 was significantly longer in So-Su than Su-So (average increase of 2.66 months, 95\%CI, 1.01$4.3, p=0.003)$. Drawbacks are as follows: First, study inclusion criteria were not clear and lack of a robust quality assessment. Second, there were no assessments of methodological quality, including the evaluation of statistical heterogeneity across the studies. Third, only a few studies were included and they had small sample sizes. Worse still, Dudek et al [9] calculated time to progression rather than progression-free survival, so that cannot be combined with overall PFS1 and PFS2. And they also included four prospective single-arm designed studies which not compared So-Su to Su-So in the analysis. Last but not least, the effect magnitude of this meta-analysis was mean differences in progression-free survival and 95\%CI from commencement of both first- and secondline treatment, neither median survival ratio nor hazard ratio. OS was not included as an outcome of this review. All of these methodological flaws in the review made the reliability of this conclusion unclear.

Based on divergent results and defective former meta-analysis, we update this meta-analysis with four new eligible researches. Meanwhile, we estimated HR in more scientific outcomes: PFS1, PFS2, PFS and OS.

Notably, our finally result is consistent with randomized controlled trial SWITCH [13] and the largest retrospective study [14], not former meta-analysis, suggests no cross-resistance between Sorafenib and sunitinib, and both of them are available to mRCC, although with overlapping but not identical kinase inhibition profiles (Table 3). Moreover, one key challenge in this meta-analysis is to interpret the result of PFS2, which was statistically longer for So-Su than Su-So. The reasons for this difference are not clear. According to Eichelberg et al [13] reported more participants received second-line treatment in So-Su than Su-So (57\% vs $42 \%$; $p<0.01$ ), which may be a reason. Patients receiving sorafenib in first-line are more likely to receive subsequent therapies than those receiving first-line sunitinib [10, 24]. Thus, the result for PFS2 should therefore be interpreted carefully.

The most frequently recording adverse events for sorafenib were diarrhea, hand-foot skin reaction. As for sunitinib, there were diarrhea, fatigue, hypertension, and nausea. All of them were consistent with previous records $[25,26]$. Buchler et al [16] reported that overall adverse serious events for sorafenib and sunitinib were statistically lower if the agent was used as the second therapy $(P=$ 
Table 3: The kinase inhibition profiles of Sorafenib and Sunitinib

\begin{tabular}{|l|l|l|}
\hline \multicolumn{1}{|c|}{ Target place } & \multicolumn{1}{|c|}{ Sorafenib } & Sunitinib \\
\hline Tumor cells & CRAF, BRAF, BRAF V600E, c-KIT, FLT-3 & c-KIT, CSF-1R, RET \\
\hline Vascular endothelium & CRAF, VEGFR-2, VEGFR-3, PDGFR- $\beta$ & $\begin{array}{l}\text { PDGFR- } \alpha, \quad \text { PDGFR- } \beta, \quad \text { VEGFR-1, VEGFR-2, } \\
\text { VEGF-3 }\end{array}$ \\
\hline
\end{tabular}

Abbreviations: CSF-1R, colony stimulating factor receptor; FLT-3, Fms-like tyrosine kinase 3; KIT, stem cell factor receptor; PDGFR, platelet- derived growth factor; RET, glial cell-line derived neurotrophic factor receptor; VEFFR, vascular endothelial growth factor receptor.

0.031 for sunitinib and $P<0.001$ for sorafenib). The rate of serious adverse events was significantly lower for So-Su than vice versa $(P<0.001)$. This indicates crosstolerance and adaptation were existed between sorafenib and sunitinib probably.

Some limitations of this meta-analysis should be taken into consideration when interpreting the results. This is a meta-analysis based on several original studies rather than individual patient data, although we have tried our best to contact the authors. Second, this analysis is based on retrospective studies and potentially could exist selection and treatment bias due to the retrospective heterogeneous nature. Third, some studies only reported median PFS rather than HR and also cannot be estimated indirectly. Thus, these studies were not synthesized that carry potential publication bias. Forth, the funnel plot which can be used to assess potential publication bias was not performed, due to the small numbers of studies. Finally, subgroup analyses such for race, age, sex, Eastern Cooperative Oncology Group performance status, Memorial Sloan Kettering Cancer Center risk score and other baseline characteristics were not sub-group analyzed, because of the raw data limitation. Further meta-analysis based on individual patient data are expected to deal with this clinical heterogeneity problem.

Given the conclusions of this analysis, sequential therapy with sorafenib and sunitinib is well tolerated and efficient in mRCC. However, there are no evidence supported that sorafenib-sunitinib has the superiority to sunitinib-sorafenib in sequence. The ideal sequence of targeted agents requires further elucidation.

\section{MATERIALS AND METHODS}

\section{Search strategy}

We systematically searched PubMed, Embase, Cochrane Library and ClinicalTrails.gov for relevant studies published between Jan 1, 2006 and Oct 13, 2016. There were no language constraints. Search text and Medical Subject Headings included sorafenib, sunitinib, and metastatic renal cell carcinoma. The complete search strategy used for PubMed was: (("Carcinoma, Renal Cell'[Mesh] AND metastatic [Title/Abstract]) AND Sorafenib [Title/Abstract]) AND Sunitinib [Title/ Abstract]. In addition, we also did a manual search using the reference lists of key literatures and the website of American Society of Clinical Oncology (ASCO).

\section{Study selection and data extraction}

We included eligible studies if they were done in patients with $\mathrm{mRCC}$, definitely compared So-Su to SuSo treatment, and reported the time from start of the first receptor tyrosine kinase inhibitor (rTKI) to the first progression (first-line progression-free survival, PFS1) or the time from start of the second rTKI to second progression or death during second-line therapy (secondline progression-free survival, PFS2) or the time from start of the first rTKI to second progression or death by any cause during second-line therapy (total progression-free survival, PFS) or the time from start of the first rTKI to death by any cause (overall survival, OS), irrespective of the types of studies. Exclusion criteria were considered as follows: single-arm designed research; studies that less than 10 patients in one arm; duplicate publications; studies that were not definitely designed as So-Su and $\mathrm{Su}-$ So group, especially for those articles that were designed in an inappropriate or ambiguous way. The outcomes assessed were PFS1, PFS2, PFS and OS.

Eligibility assessments of study tittles and abstracts were performed independently by two reviewers, and studies that potentially complied with predefined eligibility criteria were retrieved for full-text assessment. Finally, certified articles were extracted for further details as follow: the type of studies, follow-up duration, race, total number of participants, So-Su numbers, Su-So numbers, age, sex, clear-cell rate, PFS1, PFS2, combined PFS, OS and the number of participants with serious adverse events. Trials selection and data extraction were analyzed by two contributors with an agreement vale of 95.6\%; disagreements between reviewers were resolved by a third expert. Meanwhile, two independent reviewers also assessed risk for bias according to the Newcastle- 
Ottawa Scale (NOS) [27]. The final NOS assessments were reported as a score between 0 and 9 .

\section{Statistical analysis}

We performed this meta-analysis in four major outcomes: PFS1, PFS2, PFS and OS. We analyzed PFS1, PFS2, PFS and OS as time-to-event data; hazard ratio (HR) and 95\% confidence intervals $(95 \% \mathrm{CI})$ acquired directly or indirectly (in accordance with Tierney [28] reported methods) were used to compare results. When meta-analysis was not available, a qualitative synthesis may be done.

We calculated pooled estimates of the HR in PFS1, PFS2, PFS and OS between sequential therapy groups by using random- or fixed- effects model depending on the heterogeneity of the pooled studies. A fixed-effect model (inverse variance method) was applied when substantial heterogeneity not observed. Otherwise, random-effect model (DerSimonian-Laird method) was performed. Account for the differential of study design, we analyzed randomized controlled trials and retrospective studies separately.

Chi-squared Q statistics and I-square testing were used to assess heterogeneity between included trials. The moderate-to-high heterogeneity was considered when $p$ values less than 0.1 and $\mathrm{I}^{2}$ values greater than $50 \%$. We censored sensitivity by influence analysis, and omitting each study to find potential outliers. Microsoft Office Excel 2013 was used to data collecting. Statistical analysis was calculated by Stata (version 14.0).

This systematic review and meta-analysis is presented in consistent with the Preferred Reporting Items for Systematic Review and Meta-Analysis (PRISMA) Statement $[29,30]$ and was registered at International Prospective Register of Systematic Reviews (PROSPERO, CRD42016050037).

\section{Abbreviations}

mRCC: metastatic renal cell carcinoma; So-Su: sorafenib followed by sunitinib; Su-So: sunitinib followed by sorafenib; NCCN: National Comprehensive Cancer Network; ASCO: American Society of Clinical Oncology; PFS1: first-line progression-free survival; PFS2: secondline progression-free survival; PFS: total progression-free survival; OS: overall survival; NOS: Newcastle-Ottawa Scale; rTKI: receptor tyrosine kinase inhibitor; HR: hazard ratio; 95\%CI: 95\% confidence intervals; PRISMA: Preferred Reporting Items for Systematic Review and Meta-Analysis; PROSPERO: International Prospective Register of Systematic Reviews.

\section{CONFILCTS OF INTEREST}

The authors have declared no conflicts of interest.

\section{REFERENCES}

1. Le Saux O, Freyer G, Negrier S. First-Line Treatments for Poor-Prognosis Metastatic Renal Cell Carcinoma: Experts' Prescribing Practices and Systematic Literature Review. Clin Drug Investig. 2016; 36: 389-99. doi: 10.1007/s40261016-0384-0.

2. Ljungberg B, Hanbury DC, Kuczyk MA, Merseburger AS, Mulders PF, Patard JJ, Sinescu IC. Renal cell carcinoma guideline. Eur Urol. 2007; 51: 1502-10. doi: 10.1016/j. eururo.2007.03.035.

3. Tan HJ, Chamie K, Daskivich TJ, Litwin MS, Hu JC. Patient function, long-term survival, and use of surgery in patients with kidney cancer. Cancer. 2016; 122: 3776-84. doi: 10.1002/cncr.30275.

4. Logan JE, Rampersaud EN, Sonn GA, Chamie K, Belldegrun AS, Pantuck AJ, Slamon DJ, Kabbinavar FF. Systemic therapy for metastatic renal cell carcinoma: a review and update. Rev Urol. 2012; 14: 65-78.

5. Noone AM, Cronin KA, Altekruse SF, Howlader N, Lewis DR, Petkov VI, Penberthy L. Cancer incidence and survival trends by subtype using data from the Surveillance Epidemiology and End Results Program, 1992-2013. Cancer Epidemiol Biomarkers Prev. 2016. doi: 10.1158/1055-9965.epi-16-0520.

6. Motzer RJ, Jonasch E, Agarwal N, Beard C, Bhayani S, Bolger GB, Chang SS, Choueiri TK, Costello BA, Derweesh IH, Fishman M, Gallagher TH, Gore JL, et al. National Comprehensive Cancer Network. (NCCN) Clinical Practice Guidelines in Oncology. Kidey Cancer, Version 2. 2017. https://www.nccn.org/professionals/physician_gls/f guidelines.asp. Accessed 31 Oct 2016.

7. Porta C, Szczylik C, Escudier B. Combination or sequencing strategies to improve the outcome of metastatic renal cell carcinoma patients: a critical review. Crit Rev Oncol Hematol. 2012; 82: 323-37. doi: 10.1016/j. critrevonc.2011.06.001.

8. Calvani N, Morelli F, Leo S, Orlando L, Lombardi L, Gnoni A, Cinefra M, Maiello E, Lorusso V, Cinieri S. Sequential use of sorafenib and sunitinib in advanced renal cell carcinoma: does the order of sequencing matter? Med Oncol. 2012; 29: 1908-13. doi: 10.1007/s12032-011-00480 .

9. Dudek AZ, Zolnierek J, Dham A, Lindgren BR, Szczylik C. Sequential therapy with sorafenib and sunitinib in renal cell carcinoma. Cancer. 2009; 115: 61-7. doi: 10.1002/ cncr.24009.

10. Porta C, Paglino C, Imarisio I, Canipari C, Chen K, Neary M, Duh MS. Safety and treatment patterns of multikinase inhibitors in patients with metastatic renal cell carcinoma at 
a tertiary oncology center in Italy. BMC Cancer. 2011; 11: 105. doi: 10.1186/1471-2407-11-105.

11. Sablin MP, Negrier S, Ravaud A, Oudard S, Balleyguier C, Gautier J, Celier C, Medioni J, Escudier B. Sequential sorafenib and sunitinib for renal cell carcinoma. J Urol. 2009; 182: 29-34; discussion doi: 10.1016/j. juro.2009.02.119.

12. Stenner F, Chastonay R, Liewen H, Haile SR, Cathomas R, Rothermundt C, Siciliano RD, Stoll S, Knuth A, Buchler T, Porta C, Renner C, Samaras P. A pooled analysis of sequential therapies with sorafenib and sunitinib in metastatic renal cell carcinoma. Oncology. 2012; 82: 33340. doi: $10.1159 / 000338001$.

13. Eichelberg C, Vervenne WL, De Santis M, Fischer von Weikersthal L, Goebell PJ, Lerchenmuller C, Zimmermann U, Bos MM, Freier W, Schirrmacher-Memmel S, Staehler M, Pahernik S, Los M, et al. SWITCH: A Randomised, Sequential, Open-label Study to Evaluate the Efficacy and Safety of Sorafenib-sunitinib Versus Sunitinib-sorafenib in the Treatment of Metastatic Renal Cell Cancer. Eur Urol. 2015; 68: 837-47. doi: 10.1016/j.eururo.2015.04.017.

14. Alimohamed N, Lee JL, Srinivas S, Bjarnason GA, Knox JJ, Mackenzie MJ, Wood L, Vaishampayan UN, Tan MH, Rha SY, Donskov F, Tantravahi S, Kollmannsberger C, et al. A population-based overview of sequences of targeted therapy in metastatic renal cell carcinoma. Clin Genitourin Cancer. 2014; 12: e127-31. doi: 10.1016/j.clgc.2013.12.003.

15. Biondani P, Verzoni E, Torri V, Porcu L, Grassi P, Testa I, F DEB, Procopio G. Sequential Tyrosine Kinase Inhibitors (TKIs) in metastatic renal cell carcinoma: results from a large cohort of patients. Anticancer Res. 2014; 34: 2395-8.

16. Buchler T, Klapka R, Melichar B, Brabec P, Dusek L, Vyzula R, Abrahamova J. Sunitinib followed by sorafenib or vice versa for metastatic renal cell carcinoma - data from the Czech registry. Ann Oncol. 2012; 23: 395-401. doi: 10.1093/annonc/mdr065.

17. Herrmann E, Marschner N, Grimm MO, Ohlmann $\mathrm{CH}$, Hutzschenreuter U, Overkamp F, Groschek M, Blumenstengel K, Puhse G, Steiner T. Sequential therapies with sorafenib and sunitinib in advanced or metastatic renal cell carcinoma. World J Urol. 2011; 29: 361-6. doi: 10.1007/s00345-011-0673-4.

18. Porta C, Procopio G, Carteni G, Sabbatini R, Bearz A, Chiappino I, Ruggeri EM, Re GL, Ricotta R, Zustovich F, Landi L, Calcagno A, Imarisio I, et al. Sequential use of sorafenib and sunitinib in advanced renal-cell carcinoma (RCC): an Italian multicentre retrospective analysis of 189 patient cases. BJU Int. 2011; 108: E250-7. doi: 10.1111/j.1464-410X.2011.10186.x.

19. Thomas JS, Kabbinavar F. Metastatic clear cell renal cell carcinoma: A review of current therapies and novel immunotherapies. Crit Rev Oncol Hematol. 2015; 96: 52733. doi: 10.1016/j.critrevonc.2015.07.009.

20. Sonpavde G, Choueiri TK, Escudier B, Ficarra V, Hutson
TE, Mulders PF, Patard JJ, Rini BI, Staehler M, Sternberg $\mathrm{CN}$, Stief CG. Sequencing of agents for metastatic renal cell carcinoma: can we customize therapy? Eur Urol. 2012; 61: 307-16. doi: 10.1016/j.eururo.2011.10.032.

21. Ozono S, Umbas R, Akaza H, Chen JC, Chung BH, Gupta N, Hinotsu S, Horie S, Kim CS, Kwong PW, Lee JY, Lojanapiwat B, Namiki M, et al. National Comprehensive Cancer Network. (NCCN) Clinical Practice Guidelines in Oncology. Kidey Cancer, Asia Consensus Statement, Version 3. 2016. https://www.nccn.org/professionals/ physician_gls/f_guidelines.asp. Accessed 31 Oct 2016.

22. Motzer RJ, Barrios CH, Kim TM, Falcon S, Cosgriff T, Harker WG, Srimuninnimit V, Pittman K, Sabbatini R, Rha SY, Flaig TW, Page R, Bavbek S, et al. Phase II randomized trial comparing sequential first-line everolimus and second-line sunitinib versus first-line sunitinib and second-line everolimus in patients with metastatic renal cell carcinoma. J Clin Oncol. 2014; 32: 2765-72. doi: 10.1200/ jco.2013.54.6911.

23. Hutson TE, Escudier B, Esteban E, Bjarnason GA, Lim HY, Pittman KB, Senico P, Niethammer A, Lu DR, Hariharan $\mathrm{S}$, Motzer RJ. Randomized phase III trial of temsirolimus versus sorafenib as second-line therapy after sunitinib in patients with metastatic renal cell carcinoma. J Clin Oncol. 2014; 32: 760-7. doi: 10.1200/jco.2013.50.3961.

24. Filson CP, Redman BG, Dunn RL, Miller DC. Initial patterns of care with oral targeted therapies for patients with renal cell carcinoma. Urology. 2011; 77: 825-30.e1. doi: 10.1016/j.urology.2010.11.003.

25. Bhojani N, Jeldres C, Patard JJ, Perrotte P, Suardi N, Hutterer G, Patenaude F, Oudard S, Karakiewicz PI. Toxicities associated with the administration of sorafenib, sunitinib, and temsirolimus and their management in patients with metastatic renal cell carcinoma. Eur Urol. 2008; 53: 917-30. doi: 10.1016/j.eururo.2007.11.037.

26. Eisen T, Sternberg CN, Robert C, Mulders P, Pyle L, Zbinden S, Izzedine H, Escudier B. Targeted therapies for renal cell carcinoma: review of adverse event management strategies. J Natl Cancer Inst. 2012; 104: 93-113. doi: 10.1093/jnci/djr511.

27. Stang A. Critical evaluation of the Newcastle-Ottawa scale for the assessment of the quality of nonrandomized studies in meta-analyses. Eur J Epidemiol. 2010; 25: 603-5. doi: 10.1007/s10654-010-9491-z.

28. Tierney JF, Stewart LA, Ghersi D, Burdett S, Sydes MR. Practical methods for incorporating summary time-toevent data into meta-analysis. Trials. 2007; 8: 16. doi: 10.1186/1745-6215-8-16.

29. Liberati A, Altman DG, Tetzlaff J, Mulrow C, Gotzsche PC, Ioannidis JP, Clarke M, Devereaux PJ, Kleijnen J, Moher D. The PRISMA statement for reporting systematic reviews and meta-analyses of studies that evaluate health care interventions: explanation and elaboration. PLoS Med. 2009; 6: e1000100. doi: 10.1371/journal.pmed.1000100. 
30. Moher D, Liberati A, Tetzlaff J, Altman DG. Preferred reporting items for systematic reviews and meta-analyses: the PRISMA statement. PLoS Med. 2009; 6: e1000097. doi: 10.1371/journal.pmed.1000097. 